\title{
EVASÃO ESCOLAR NA EDUCAÇÃO: UM ESTUDO DE CASO DAS LICENCIATURAS DO IFRN CAMPUS NATAL-CENTRAL
}

\author{
Apresentação: Comunicação Oral
}

Rafaela Caroline Alves dos Santos, Licenciatura em Geografia - Instituto Federal de Educação, Ciência e Tecnologia do Rio Grande do Norte, e-mail, rafaellaalves00@ hotmail.com ${ }^{1}$; Mayra Raiza de Figueiredo Gonzalez, Licenciatura em Geografia- Instituo Federal de Educação, Ciência e Tecnologia do Rio Grande do Norte, email, Mayra.ifrn@gmail.com²; Rudson Max Silva Madeiro, Licenciatura em Matemática

Instituto Federal de Educação, Ciência e Tecnologia do Rio Grande do Norte, e-mail, rudsonmadeiro@gmail.com³; André Luís Firmino de Brito Barros - Instituto Federal de Educação, Ciência e Tecnologia do Rio Grande do Norte, e-mail, Andre.barros@ifrn.edu.br ${ }^{4}$

\section{Resumo}

A educação É um dos setores mais importantes para o desenvolvimento de uma nação. É através da implantação de um modelo educacional eficaz que um país cresce. Embora os avanços tenham sido relevantes nos últimos anos em nosso país neste campo, ainda há muito para ser feito. As escolas, como também as universidades, tornaram-se locais de grande importância para a ascensão social. Muitas famílias, como também o Estado tem investido muito neste setor, porém vem se verificando que nos últimos anos as taxas de evasão escolar nos cursos de licenciatura vêm tendo um aumento gradativo. A evasão é, certamente, um dos problemas que afligem as instituições de ensino em geral. A busca de suas causas tem sido objeto de muitos trabalhos e pesquisas educacionais. A evasão estudantil no ensino superior, sobretudo nos cursos de licenciatura é um problema internacional que afeta o resultado dos sistemas educacionais. As perdas de estudantes que iniciam, mas não terminam seus cursos, são desperdícios sociais, acadêmicos e econômicos. No setor público, são recursos públicos investidos sem o devido retorno. No setor privado, é uma importante perda de receitas. Em ambos os casos, a evasão é uma fonte de ociosidade de professores, funcionários, equipamentos e espaço físico. Tendo em vista esse cenário, o presente artigo centra-se sua manifestação nos cursos de licenciaturade Física e Geografia do Instituto Federal de Educação, Ciência e tecnologia do Rio Grande do Norte, campus Natal Central, cuja expressividade merece atenção especial e urgente. Os resultados serão obtidos através da análise de documentos, revisão bibliográfica e aplicação de questionário, sobretudo no ano de 2009. Espera-se ao final desse estudo encontrar possíveis respostas que expliquem o motivo da alta taxa de evasão, como também verificar as possibilidades e os meios para sanar e/ou minimizar tal problema.

Diante desses dados observa-se uma alta taxa de evasão no que se refere aos cursos aqui citados. Tal situação exige uma investigação profunda, a fim de saber quais as causas deste alto índice e quais os possíveis meios para sanar esse problema. Diante do exposto, temos como foco e objetivo principal, detectar e discutir os motivos que ocasionaram a evasão dos alunos dos Cursos de Licenciatura em Física e Geografia, ingressos no ano de 2009, no

\footnotetext{
${ }^{1}$ Graduando em Licenciatura em Geografia, IFRN, rafaellaalves00@hotmail.com

${ }^{2}$ Graduando em Licenciatura em Geografia, IFRN, Mayra.ifrn@gmail.com

${ }^{3}$ Graduando em Licenciatura em Matemática, IFRN, rudsonmadeiro@gmail.com

${ }^{4}$ Mestre em Economia, Universidade Federal do Rio Grande do Norte, Andre.barros@ifrn.edu.br
} 
Instituto Federal de Educação, Ciência e Tecnologia do Rio Grande do Norte, campus NatalCentral. 
Palavras-Chave: educação, cursos de licenciatura, evasão escolar.

\section{Introdução}

O presente trabalho visa pesquisar e estudar a evasão nos cursos de Licenciatura em Física e em Geografia oferecidos pelo Instituto Federal de Educação, Ciência e Tecnologia do Rio Grande do Norte (IFRN) campus Natal - Central a fim de detectar suas causas e propor soluções para minimizá-las.

Estudos atuais revelam que há uma tendência de evasão grande e permanente em todos os cursos de licenciatura, já que a atividade profissional do magistério no Brasil não tem se mostrado atraente diante dos baixos salários oferecidos, as precárias condições de trabalho, a falta de segurança nas escolas, o desprestígio social da atividade assim como a falta de perspectiva na carreira contribui para que cada vez menos pessoas se interessem pela profissão.

Gaioso (2005) considera que algumas profissões são altamente valorizadas, como Direito, Engenharia e Medicina, e geram expectativas de altos salários, emprego garantido, dentre outros fatores que possibilitam a ascensão de tais profissões. Em contrapartida os cursos de licenciaturas e de magistério, que são marcados pela falta de prestígio social, além dos outros percalços citados anteriormente, são afetados diretamente com os altos índices de evasão.

Moura e Silva, afirmam:

De acordo com ister alta, e por vários fatores, que vão desde as repetências sucessivas nos primeiros anos, até a falta de recursos para os alunos se manterem, mesmo numa universidade pública (2007, p. 31).

Como recurso inicial a problemática proposta, é de relevância esclarecer que dos 39 alunos matriculados no curso de Licenciatura em Física no ano de 2009, 15 destes evadiram-se, tendo assim uma taxa de aproximadamente 38,5\% de evasão, na Geografia foram 38 alunos matriculados, 15 evadidos, tendo assim, 39,5\% de evasão.

Diante desses dados observa-se uma alta taxa de evasão no que se refere aos cursos aqui citados. Tal situação exige uma investigação profunda, afim de saber quais as causas deste alto índice e quais os possíveis meios para sanar esse problema. Diante do exposto, temos como foco e objetivo principal, detectar e discutir os motivos que ocasionaram a evasão dos alunos dos Cursos de Licenciatura em Física e Geografia, ingressos no ano de 2009, no Instituto Federal de Educação, Ciência e Tecnologia do Rio Grande do Norte, campus Natal-Central.

\section{Fundamentação Teórica}


A educação faz parte da vida do homem na sociedade, serve de guia para uma boa convivência social e o capacita para poder transmitir conhecimentos; é, portanto, fator principal na formação da sociedade. "A educação está situada no coração do desenvolvimento do ser humano, fazendo frutificar os seus talentos e potencialidades criativas, o que implica acapacidade de cada um em responsabilizar-se pela realização do seu projeto pessoal”. (SILVA, 2002. p. 42)

A educação tem o objetivo de dotar o homem de instrumentos culturais capazes de impulsionar as transformações materiais e espirituais exigidas pela dinâmica da sociedade, não se restringindo somente ao conhecimento sistemático adquirido dentro de uma instituição de ensino. Ninguém escapa da educação: seja em casa, na rua, na igreja ou na escola, todos aprendem alguma coisa, independentemente do meio em que vive. A educação desenvolve e forma a personalidade humana atuando em todos os aspectos, começando na família, continuando na escola e se prolongando por toda existência. Ela forja no homem a capacidade crítica, permitindo o livre pensamento e uma ação autônoma. (BRANDÃO, 1985; DELORS, 2001; KRAEMER, 2005)

O processo de aprendizagem é contínuo, não para com o tempo ou com o espaço; a educação é constante, independentemente de linha ideológica, posição política ou interesse econômico. O homem está sempre buscando inovações, e promovendo transformações; trocando conhecimentos no processo "aprender-ensinar-e-aprender". Assim, a educação aparece sempre que há relações entre pessoas e intenções de ensinar-e-aprender. (BRANDÃO, 1985; CUNNINGHAM, 1975; FREIRE, 2001)

Apesar de todos estes atributos vinculados à educação, a evasão universitária é um fenômeno que se torna cada vez mais comum em universidades privadas de todo o mundo, independentemente das peculiaridades socioeconômicas e culturais de cada país e das diferenças entre as diversas instituições de ensino. A África do Sul, por exemplo, apresenta uma taxa de $40 \%$ de abandono dos estudantes universitários no primeiro ano de graduação. Sendo as principais causas deste, segundo Macgregor (2007), as dificuldades financeiras enfrentadas pelos alunos além da baixa escolaridade e renda da família na qual estão inseridos.

Já no continente europeu, de acordo com Garner (2007), a Irlanda apresenta a menor taxa de evasão universitária, seguida pela Inglaterra. Em termos mundiais, o país com a menor taxa de evasão é o Japão. Interessante que uma das maiores taxas de abandono entre os países desenvolvidos está nos Estados Unidos, onde apenas aproximadamente 50\% dos jovens dão continuidade ao ensino superior, uma vez que as faculdades naquele país permitem uma ampla flexibilidade na formação, o que deveria minimizar o abandono pelo efeito da opção errada pelo curso. 
No Brasil, segundo Almeida e Veloso (2002), em alguns casos, o baixo desempenho no ensino médio reflete no desempenho das primeiras disciplinas do curso superior, resultando em abandono do curso pelas reprovações nos primeiros semestres. Outro fator seria o fato de o aluno buscar o curso de baixa demanda com o objetivo de, após ter ingressado, procurar o curso de sua verdadeira opção, através da transferência interna. Como isto às vezes não é viabilizado, principalmente pela não oferta de vaga para este tipo de ingresso, o aluno busca um novo concurso vestibular em outra instituição.

Nassar et al. (2003) afirmam que a evasão universitária no Brasil apresenta um índice muito elevado, cerca de 40\%, o que leva a crer que as Instituições de Ensino Superior (IES) não estão se ocupando adequadamente deste fenômeno, não só na gestão dos cursos já existentes, como também na abertura de novos cursos. Já para Vieira e Frigo (1991) a principal causa da evasão poderia ser a reforma do antigo ensino de $2^{\circ}$ grau, que viabilizou o ingresso precoce de muitos jovens nas universidades, o que os levou à escolha prematura de um curso, quando ainda desconhecem todo o potencial de suas aptidões, motivações e interesses. Uma outra causa apontada por Vieira e Frigo (1991), é o fato de muitos universitários serem "trabalhadores-estudantes", em que a dificuldade de conciliar o trabalho, que é o meio necessário para a subsistência, com os estudos, muitas vezes torna-se inviável e se tratando de cursos de licenciatura, as causas da evasão são ainda mais numerosas. Vivemos em um contexto social, onde o papel do professor é de extrema desvalorização, os salários são baixíssimos, as escolas não oferecem uma estrutura física de qualidade que permita o professor desempenhar com excelência se trabalho.

Baixo prestígio da profissão, baixos salários, dificuldades financeiras dos estudantes para permanecerem no campus, qualidade pedagógica dos docentes, pouca atratividade dos cursos, currículos inchados, repetitivos e desarticulados, distanciamento entre teoria e prática, matematicidade dos cursos, baixa qualidade do ensino médio - que contribuem para a mobilidade, se não para a exclusão e, por isso, precisam ser adequadamente trabalhadas (Adachi, 2009, p. 61).

Ainda neste contextoAdachi afirma, "em cursos como os de Licenciatura, mesmo que o estudante se sinta vocacionado para determinada profissão, ele tende a mudar de curso, em função das potenciais dificuldades profissionais por ele vislumbradas" $(2009$, p. 30).

De acordo com Mazzetto e Carneiro, o Censo do Ensino Superior revela que

A sobra de vagas é predominantenos cursos de Licenciatura, pouco atraentes para quem está ingressandono ensino superior. O desinteressepelas áreas de Licenciatura pode estarsendo influenciado pela baixa qualidade do ensino e pelo surgimento de novas carreiras, sinalizando que estes cursos precisam melhorar sua qualidade, já que faltam professores qualificados para dar aulas no ensino fundamental e no ensino médio. Cerca de 
830 mil professores desses dois níveis de ensino não possuem formação superior (2002, p. 1207).

Abordando por outro prisma, Silva (2006) indica que a magnitude da evasão está diretamente relacionada com a qualificação do corpo docente e não somente ao status socioeconômico dos estudantes. Ainda, para ele, os jovens amadurecem mais tarde e algumas vezes fazem escolhas prematuras no que diz respeito ao seu futuro profissional, sendo que muitos deles sofrem da síndrome da adolescência prolongada e que por volta dos trinta anos muitas pessoas reveem seus objetivos de vida. Na Tabela 1, fica claro essa alta magnitude da evasão, nos cursos de licenciatura, citada acima por Silva, principalmente nas disciplinas/cursos de matemática, física, química e biologia.

\section{Figura 1: Percentual de evasão nos cursos de licenciatura (Fonte: MEC/INEP/CAPES 1997)}

\begin{tabular}{l|c}
\hline \multicolumn{1}{c|}{ Curso } & $\begin{array}{c}\text { Percentual de } \\
\text { Evasão }\end{array}$ \\
\hline Licenciatura em Matemática & $56 \%$ \\
Licenciatura em Química & $75 \%$ \\
Licenciatura em Física & $65 \%$ \\
Licenciatura em Biologia & $42 \%$ \\
Licenciatura em História & $44 \%$ \\
Licenciatura em Geografia & $47 \%$ \\
Licenciatura em Letras & $50 \%$ \\
Licenciatura em Educação Artistica & $52 \%$ \\
\hline
\end{tabular}

A pesquisa desenvolvida por Theóphilo e Moraes (2005) complementa a de Silva ao revelar que a evasão no início do curso estaria, normalmente, relacionada à dificuldade do aluno em se adaptar as exigências dos professores e à mudança do ensino médio para o superior. Já quando os alunos evadem por volta do quarto e do sexto semestres, geralmente é porque começaram a se questionar sobre o sentido da profissão (THEÓPHILO; MORAES, 2005, p. 6).

No entanto, Biazus (2004 apud SILVA, 2006), afirma que os fatores da evasão discente se manifestam em graus distintos nos mais variados cursos das IES e que não há uma lógica uniforme que explique a homogeneidade em sua ocorrência no conjunto dos cursos, uma vez que esses fatores estão relacionados a características individuais, como a vocação e outros problemas de ordem pessoal, a fatores internos, referente aos recursos humanos, aspectos didático-pedagógicos e 
à infraestrutura, e a fatores externos às Instituições de Ensino Superior, ligados a aspectos sóciopolítico-econômicos.

Em síntese, a evasão é uma problemática que tem levado muitos estudiosos a pesquisarem as suas causas, a fim de que possam ser encontradas alternativas para as mazelas que se originam deste

processo. E, apesar das semelhanças e diferenças existentes entre os autores, todos concordam que as instituições de ensino superior, sobretudo as que oferecem cursos de licenciaturas devem adotar processos de gestão que sejam corretivas e preventivas da evasão, reduzindo assim os índices de abandono dos mesmos. E, para tal, é fundamental a compreensão dos motivos que condicionam a evasão.

\section{Metodologia}

Para alcançar o objetivo delineado, inicialmente, será realizada uma busca e análise de documentos relativos ao tema em questão e uma revisão bibliográfica para fundamentar o nosso trabalho. Nessa fase, com a ajuda do sistema acadêmico da escola, também serão coletados os dados quantitativos inerentes ao fluxo dos estudantes dos Cursos de Licenciatura em Física e Geografia do IFRN, Campus Natal-Central, que ingressaram no ano de 2009 através do Exame Nacional do Ensino Médio (Enem), visto que nos anos anteriores a 2009 utilizavam-se outras formas de ingresso.

Em seguida, elaboraremos um roteiro básico para dar suporte às entrevistas semiestruturadas que serão realizadas com os estudantes que interromperam definitivamente suas trajetórias acadêmicas no âmbito deste nível de escolaridade. Portanto, como podemos constatar, nosso estudo envolverá a utilização de métodos de análise tanto quantitativa, quanto qualitativa.

A entrevista também será escolhida como técnica de coleta de dados porque, segundo Lakatos (2003), trata-se de uma conversação efetuada face a face, de maneira metódica, que pode proporcionar resultados satisfatórios e informações necessárias. Por meio da entrevista pode-se conhecer o significado que o entrevistado dá aos fenômenos e eventos de sua vida, utilizando seus próprios termos. Essa técnica permitirá a coleta de dados importantes que não se encontram em fontes documentais e nem podem ser coletados por meio de outra técnica ou instrumento.

Com o objetivo de realizar a triangulação de sujeitos e de técnicas/instrumentos, também serão ouvidos professores dos cursos a respeito das causas da evasão dos estudantes, onde serão aplicados questionários aos mesmos. 


\section{Resultados e Discussão}

Em relação aos resultados, espera-se que ao final deste projeto, que está em fase de desenvolvimento, seja promovido o engajamento de pesquisadores, com o objetivo de investigar o desenvolvimento e desempenho da educação, com vistas à formulação de parâmetro e políticas educacionais para esta e outras modalidades de ensino.

Além disto, podem ainda trazer uma contribuição para a formação de profissionais com capacidade de produzir avaliações qualitativas e abrangentes para a educação brasileira.

Como resultado concreto deste trabalho contará com a publicação de artigos científicos, propostas de intervenção local e participação em eventos ligados ao tema para que novos direcionamentos sejam apontados paraa construção de uma política efetiva de combate aos problemas da educação.

A disseminação dos resultados será através da revista Holos do IFRN, bem como na submissão do artigo em eventos científicos, além da divulgação através de banners e vídeos na Exposição Científica, Tecnológica e Cultural (EXPOTEC). Como parte integrante da divulgação, também utilizaremos o portal do IFRN e outros meios institucionais, fazendo com que haja o incentivo para que outros campi do IFRN e outras instituições de ensino promovam propostas de intervenção local, não somente para os alunos das Licenciaturas, mas também para os diversos cursos ofertados pela Rede Federal de Educação Profissional, Científica e Tecnológica e das redes estaduais, distritais e municipais de educação profissional e tecnológica. Com isso, ao final deste projeto de pesquisa, alcançaremos o trinômio Ensino, Pesquisa e Extensão.

\section{Conclusões}

Ao final desta pesquisa, que por vez encontra-se em andamento, esperamos que sejam desvendados os principais motivos para esse alto índice de evasão escolar na instituição IFRNCNAT, assim como buscar estratégias para reduzir a saída desses alunos dos cursos de licenciatura.

\section{Referências}

ADACHI, A.A.C.T. 2009.Evasão e evadidos nos cursos de graduação da UFMG. Belo Horizonte, MG. Dissertação de Mestrado. Universidade Federal de Minas Gerais, 214 p. 
ALMEIDA, Edson Pacheco; VELOSO, Tereza Christina M. A. Evasão nos cursos degraduação da Universidade Federal de Mato Grosso, campus universitário de Cuiabá: um processo de exclusão. Cuiabá: UFMT, 2002.

CUNNINGHAM, William F. Problemas fundamentais , finalidades e técnicas. Rio de Janeiro: Globo/MEC, 1975, p.6.

CUNNINGHAM, William F. Problemas fundamentais , finalidades e técnicas. Rio de Janeiro: Globo/MEC, 1975, p.6

FREIRE, Paulo. Política e educação. 5 ed. São Paulo: Cortez, 2001. 119 páginas.

GAIOSO, N.P.L. 2005. O fenômeno da evasão escolar na educação superior no Brasil. Brasília, DF. Dissertação de Mestrado. Universidade Católica de Brasília, 75 p

GARCIA, Hamílcar de. Dicionário Caldas Aulete. 5 ed. Rio de Janeiro: DELTA S.A., 1987. p. 628.

GARNER, Richard. More than $\mathbf{1 0 0 . 0 0 0}$ students drop out of university after first year. 2007. Disponível em: <http://www.independent.co.uk/news/education/education-news/more-than100000-students-drop-out-of-university-after-first-year-458758.html>. Acesso em: 25 dez. 2012. LAKATOS, Eva Maria. Fundamentos de Metodologia Científica. $5^{\text {a }}$ ed. São Paulo: Atlas.

MAZZETO, S.E.; CARNEIRO, C.C.B. 2002. Licenciatura em Química da UFC: perfi 1 socioeconômico, evasão e desempenho dos alunos. Quimíca Nova, 25(6B):1204- 1210. http://dx.doi.org/10.1590/S0100-40422002000700024

MEC; INEP; CAPES.1997. Censo da Educação Superior de 1997. Disponível em: http://portal.inep.gov.br/web/censo- da-educacao-superior/. Acesso em: 24/08/2014.

MOURA, D.H.; SILVA, M.S. 2007. A evasão no curso de licenciatura em Geografia oferecido pelo CEFET-RN. Holos, 23(3):26-42.

NASSAR, Silvia M; NETO, Eugênio R; CATAPAN, Araci H; PIRES, Maria M. S. Inteligência Computacional aplicada a Gestão Universitária: Evasão Discente. 2003. Disponível em: <http://www.inpeau.ufsc.br/coloquio>. Acesso em: 25 dez. 2012.

SILVA, Renato. Deserción: Competitividad ó Gestion. Revista Lasallista de Investigación. Colômbia, v.2, p.64-69, 2006. 